\title{
PELATIHAN SEBAGAI UPAYA PENINGKATAN MUTU TENAGA KEPENDIDIKAN DI LINGKUNGAN DINAS PENDIDIKAN PROVINSI DAERAH KHUSUS IBUKOTA JAKARTA (Studi di Pusat Pengembangan Manajemen Sekolah, 2016)
}

\author{
Awalien Dhea Syafitrie, Amril Muhammad, Siti Rochanah \\ awalien.dhea.sy@gmail.com
}

\begin{abstract}
This research aimed to describe the planning and execution of training in improving the quality of education personnel in Jakarta. Research on quality managament be specified in two sub research focus is the planning of training and implementation of training activities in PPMS. The method used is a qualitative case research. The data obtained by researchers is through observation, depth interviews (depth interview), and documentation research. Key informant interviews were conducted at the Head Centre and supported by the informant support consists of the Head of Administration, Head of Executive Management Development Medium, instructor and trainees.
\end{abstract}

The research concluded that 1) Planning of training undertaken in an effort to improve the quality of education personnel through the stages of training needs analysis, a coordination meeting between the committee and implementing units, define the training objectives, determining the training target, specify the subject matter, time, and number of participants, determine More specifically instructor with the materials according to their fields of expertise. Resulting from this process that the terms of reference of activities and proposal activities, criteria for participants and instructors criteria, the list of participants will be invited, syllabus and training schedules, training materials by the instructor, training rules and list of required facilities and infrastructure. 2) Implementation of the training activities carried out through pre-test phase - IN 1 - On the Job Learning - IN 2 - Post test up until the evaluation results come out in the form of certificates to the participants assessment. Output generated in the form of training implementation Accountability report along with photo documentation of training activities.

PPMS should conduct a detailed analysis of requirement operating more hearts held trainin, set time allocation complex material material adjustments and trainer right, make a detailed schedule and disseminate the material shown to the participants which impacted the increasing skills from the training participants.

Keywords: Training, Planning of Training, Implementation Training Activities.

\section{Pendahuluan}

Salah satu usaha dalam peningkatan dan pengembangan sumber daya manusia adalah melalui pelatihan. Pelatihan merupakan bagian dari pendidikan. Pendidikan yang lebih bersifat filosofis dan teoritis. Sama halnya seperti pendidikan, pelatihan memiliki tujuan yang sama yaitu, Pembelajaran, dimana seseorang dimungkinkan untuk menjadi seorang innovator, pengambil inisiatif pemecah 
masalah yang kreatif, serta menjadikan seseorang efektif dan efisien dalam melakukan pekerjaan.

Menurut informasi yang diperoleh peneliti dari hasil grandtour, pada tahun 2002 sesuai SK Gubernur Nomor 95 Tahun 2002 terbentuklah Balai Pelatihan Tenaga Kependidikan Dasar yang telah berubah nomenklaturnya sesuai dengan Peraturan Gubernur Provinsi DKI Jakarta Nomor 51 Tahun 2010 menjadi Pusat Pelatihan Guru dan Tenaga Kependidikan yang kemudian disingkat dengan PPGTK. PPGTK merupakan salah satu unit pelaksana Teknis Dinas Pendidikan dengan salah satu tugas pokok dan fungsinya yaitu sebagai penyelenggara berbagai pelatihan kepada guru dan tenaga kependidikan di Provinsi DKI Jakarta.

Dengan semakin majunya perkembangan zaman di dunia Pendidikan di Indonesia maka Pusat Pengembangan Manajemen Sekolah Provinsi DKI Jakarta berproses melalui perubahan Struktur Lama yaitu Pusat Pelatihan Guru dan Tenaga Kependidikan (PPGTK) dan pengembangan struktur Unit Pelaksana Teknis dilingkungan Dinas Pendidikan Provinsi DKI Jakarta Nomor 340 Tahun 2014 pada tanggal 31 Desember 2014 tentang Pembentukan Organisasi dan Tata Kerja Pusat Pengembangan Manajemen Sekolah (PPMS).

Pusat Pengembangan Manajemen Sekolah yang kemudian disebut PPMS, yaitu organisasi yang keberadaannya berada di bawah dan bertanggungjawab kepada Kepala Dinas Pendidikan Provinsi DKI Jakartadan dipimpin oleh Seorang Kepala Pusat yang mempunyai tugas pokok yaitu melaksanakan Pendidikan dan Pelatihan, Pengkajian, dan Pengembangan Manajemen Sekolah.
Sesuai dengan salah satu tugas pokok dari PPMS, yaitu melaksanakan pendidikan dan pelatihan, terhitung dari tahun 2010 sampai dengan 2015 PPMS sudah melaksanakan 91pelatihan. Dengan rincian 80 pelatihan saat masih dengan nama PPGTK pada tahun 2010 sampai dengan 2015 dan 12 pelatihan sebagai PPMS.

Dari semua pelatihan yang telah dilaksanakan oleh PPMS, melalui proses kegiatan dilakukan berdasarkan struktur persiapan, pelaksanaan, hasil dan tindak lanjut. Dalam tahap persiapan, kegiatan yang dilakukan adalah penyusunan kerangka acuan, penyusunan proposal kegiatan, penyusunan program umum, pokok dan penunjang, penentuan kriteria peserta, penentuan kriteria penatar, hubungan instansional, pemanggilan peserta, penyusunan buku panduan, inventarisasi materi dan sarana-prasarana. Dalam tahap pelaksanaan kegiatan yang dilakukan adalah pengarahan inti, pengarahan teknis, pendidikan dan latihan: negosiasi, pre test, post test, sidang pleno, sidang kelompok, tugas mandiri, dan simulasi pembelajaran.

Dengan demikian nampak pelaksanaan pelatihan dalam upaya peningkatan tenaga kependidikan yang bermutu dan memiliki standar kompetensi yang harus dimiliki tidak terlepas dari proses perencanaan yang matang. Untuk melakukan pelatihan yang maksimal perlu koordinasi yang lebih intens dan persiapan yang optimal untuk memaksimalkan proses pembelajaran yang lebih baik dan manfaat pelatihan dapat dirasakan oleh peserta pelatihan.

Berangkat dari hal yang telah dipaparkan di atas, menarik perhatian peneliti untuk mengangkat fenomena tersebut. Peneliti tertarik mengusung tema peningkatan mutu tenaga kependidikan. Penelitian dilakukan untuk mengetahui bagaimana peningkatan 
mutu secara nyata untuk tenaga kependidikan DKI Jakarta. Penelitian dilakukan di Lingkungan Dinas Pendidikan Provinsi Daerah Khusus Ibukota Jakarta. Adapun judul penelitian ini adalah 'Pelatihan Sebagai Upaya Peningkatan Mutu Tenaga Kependidikan di Lingkungan Dinas Pendidikan Provinsi Daerah Khusus Ibukota Jakarta",

Berdasarkan latar belakang masalah tersebut, penelitian ini difokuskan pada manajemen mutu, dengan subfokus yang meliputi perencanaan pelatihan dan pelaksanaan pelatihan di PPMS. Adapun manfaat dari penelitian ini yaitu: (1) sebagai bahan kajian untuk pengembangan ilmu pengetahuan terkait proses perencanaan dan pelaksanaan kegiatan pelatihan Tenaga Kependidikan, (2) sebagai masukan atau rekomendasi yang bermanfaat bagi Kepala Pusat, Pegawai serta Instruktur di Pusat Pengembangan Manajemen Sekolah Dinas Pendidikan Provinsi DKI Jakarta dalam pelaksanaan upaya meningkatkan mutu pelatihan tenaga kependidikan, (3) menambah pengalaman dan pengetahuan peneliti setelah membandingkan hasil temuan dari kegiatan di lapangan dengan teori yang diperoleh dari sumber - sumber yang relevan.

\section{Kajian Teori}

Menurut Stoner, Edward, dan Gilbert (1994:7), "Management: the process of planning, organizing, leading, and controlling the work of organization members and using all available organization resources to reach stated organization goals". Robbins dan Coulter (1999:8) mengemukakan manajemen adalah proses pengkoordinasian dan mengintegrasikan kegiatan-kegiatan kerja agar diselesaikan secara efisien dan efektif dengan dan melalui orang lain.
Menurut Daft (1997:8), "management is the attainment of organizational goals in effective and efficient manner through planning, organizing, leading and controllong organizational recources". Definisi yang dikemukakan oleh Jones dan George (2003:5), "management is the planning, organizing, leading, and controlling of human and other resources to achieve organizational goals effectively and efficiently". Menurut Goetsch dan Davis yang dikutip oleh Tjiptono dan Diana (2013:4), "mutu adalah suatu kondisi dinamis yang berhubungan dengan produk, jasa, manusia, proses, dan lingkungan yang memenuhi atau melebihi harapan".

Menurut Crosby, seperti dikutip oleh Ross (1995:6), mutu adalah: (1) Sesuatu yang sesuai dengan yang disyaratkan atau dibutuhkan, bukan kebaikan; (2) Sistem untuk mencapai mutu adalah pencegahan, bukan penaksiran; (3) Tampilan baku dengan prinsip tanpa cacat, bukan hanya mendekati kecukupan; (4) Ukuran mutu adalah nilai ketidaksesuaian, bukan sesuatu nilai yang diurut-urutkan (indexes). Menurut Juran yang dikutip oleh Ross (1995:6), mengemukakan bahwa mutu adalah kesesuaian manfaat dengan rancangan, kebutuhan, ketersediaannya, keamananannya, dan kegunaan umumnya. Ross (1995:97) mengutip pendapat Garvin yang menganjurkan lima pendekatan untuk mendefinisikan mutu, yaitu suatu kondisi dinamis yang berhubungan dengan: (1) Produk (product-based), (2) Manusia/tenaga kerja (user-based), (3) Proses (manufacturing-based), (4) Tugas, (5) Lingkungan yang memenuhi atau melebihi harapan pelanggan atau konsumen (transcendent and value-based).

Jones dan George (2003:380) mendefinisikan pelatihan sebagai, "Teaching organizational members gow to perform their current jobs 
and helping them acquire the knowledge and skills tey need to be effective performers." Menurut Dessler yang dikutip Tohari (2015:19), "Training refers to the methods used to give new or present employees the skill they need to perform their jobs".

Menurut Bernardin dan Russel yang dikutip Tohari (2015:19), menyatakan bahwa pelatihan adalah untuk memperbaiki penguasaan berbagai keterampilan dan teknik pelaksanaan kerja tertentu, terinci, rutin, dan yang dibutuhkan sekarang. Menurut Milkovich dan Doudreau (1994:490), "Training is a systematic process to foster the acquisition of skills, rules, concepts, or attitudes that result in an improved match between employee characteristics and employment requirements".

Omocharu dan Ross (1994:70) mengungkapkan untuk melihat mutu pelayanan dapat menggunakan pengukuran mutu pelayanan yang mencakup: (1) Performance, (2) Features, (3) Reability, (4) Conformance, (5) Durability,

Serviceablity, (7) Aesthetics, (8) Perceived and Quality.

Robbin dan Coulter (1999:200) menyatakan bahwa perencanaan adalah suatu proses yang melibatkan penentuan sasaran atau tujuan organisasi, menyusun strategi menyeluruh untuk mencapai sasaran yang ditetapkan, dan mengembangkan hierarki rencana secara menyeluruh untuk mengintegrasikan dan mengkoordinasikan kegiatan.

Menurut Daft (1997:214), "planning is the act of determining the organization's goals and the means for achieving them". Kemudian dinyatakan oleh Stoner dkk (1994:263) bahwa, "Planning is a particular kind of decision making that addresses the specific ruture that managers desire for their organizations."

Menurut Robbin dan Coulter (1999:201), jenis-jenis perencanaan dapat dibedakan berdasarkan luasnya (strategis lawan operasional), Kerangka waktu (jangka pendek lawan jangla panjang), kekhususan (pengarahan lawan khusus), dan frekuensi penggunaan (dipakai sekali lawan terus menerus).

Menurut pendapat Daud (2004:3), semua kegiatan perencanaan pada dasarnya melalui beberapa tahapan, antara lain yaitu: (1) Menyadari kesempatan, (2) Menetapkan tujuan atau serangkaian tujuan, (3) Menentukan Dasar Fikiran (premis), (4) Menentukan Arah-arah Tindakan Alternatif, (5) Mengevaluasi Arah-arah Tindakan Alternatif, (6) Memilih suatu Arah Tindakan Alternatif, (7) Merumuskan Rencanarencana Turunan, serta (8) Mengurutkan Rencana-rencana Berdasarkan Anggaran.

Majone dan Wildavsky yang dikutip Usman (2002:70) menyatakan pelaksanaan sebagai evaluasi, pelaksanaan adalah suatu tindakan atau pelaksanaan dari sebuah rencana yang sudah disusun secara matang dan terperinci, implementasi biasanya dilakukan setelah perencanaan sudah dianggap siap. Menurut Syukur (2000:10), Pelaksanaan merupakan aktifitas atau usaha-usaha yang dilaksanakan untuk melaksanakan semua rencana dan kebijaksanaan yang telah dirumuskan dan ditetapkan dengan dilengkapi segala kebutuhan, alat-alat yang diperlukan, siapa yang melaksanakan, dimana tempat pelaksanaannya mulai dan bagaimana cara yang harus dilaksanakan, suatu proses rangkaian kegiatan tindak lanjut setelah program atau kebijaksanaan ditetapkan yang terdiri atas pengambilan keputusan, langkah yang strategis maupun operasional atau kebijaksanaan menjadi kenyataan guna 
mencapai sasaran dari program yang ditetapkan semula.

Menurut pendapat Wahab (2001:65), pelaksanaan adalah tindakan-tindakan yang dilakukan oleh individu atau pejabat-pejabat, kelompok-kelompok pemerintah atau swasta yang diarahkan pada terciptanya tujuantujuan yang telah digariskan dalam keputusan kebijakan. Menurut pendapat Setiawan (2004:39), pelaksanaan adalah perluasan aktivitas yang saling menyesuaikan proses interaksi antara tujuan dan tindakan untuk mencapainya serta memerlukan jaringan pelaksana, birokrasi yang efektif. Menurut pendapat Harsono (2002:67), pelaksanaan adalah suatu proses untuk melaksanakan kebijakan menjadi tindakan dari politik ke dalam administrasi. Pengembangan kebijakan dalam rangka penyempurnaan suatu program. Menurut Syukur (2000:398), faktor-faktor yang dapat menunjang program pelaksanaan terdiri dari empat faktor, yaitu: (1) Komunikasi, (2) Resouces (sumber daya), (3) Disposisi, dan (4) Struktur Birokrasi.

\section{Metodologi Penelitian}

Penelitian ini menggunakan pendekatan kualitatif dan metode deskriptif analitik. Penelitian dilakukan di sekolah Bosowa Bina Insani Bogor, jalan KH. Sholeh Iskandar, Kota Bogor. Penelitian dilaksanakan secara bertahap selama kurang lebih tiga bulan, mulai November 2015 hingga Januari 2016.

Data yang digunakan adalah data primer yang diperoleh dari pengamatan penelitian dan dikumpulkan dalam bentuk catatan lapangan, dan data sekunder yang diperoleh dari PPMS, serta dari pustaka yang relevan. Serta data sekunder diperoleh dari pengumpulan data berupa dokumendokumen pendukung penelitian. Adapun teknik pemilihan informan dilakukan dengan teknik snowball sampling dan dipilih berdasarkan pada pertimbangan memiliki jabatan dan akses informasi yang memudahkan peneliti menjelajahi objek penelitian. Informan pada penelitian ini adalah Kepala PPMS, Kepala Sub Bagian Tata Usaha, Kepala Satuan Pelaksana Pengembangan Manajemen Pendidikan Menengah, Pejabat Fungsional Umum, Instruktur dam Peserta.

Pengumpulan data dilakukan dengan teknik wawancara, observasi dan studi dokumen. Adapun tahapan penelitian dimulai dari tahap pra lapangan yang terdiri dari kegiatan (1) menyusun rancangan penelitian, (2) memilih lapangan penelitian, (3) mengurus perizinan, (4) menjajaki dan menilai keadaan lapangan, (5) memilih dan memanfaatkan informan serta (6) menyiapkan perlengkapan penelitian. Kemudian dilanjutkan dengan tahap pekerjaan lapangan yang terdiri dari kegiatan (1) memahami latar penelitian dan persiapan diri, (2) memasuki lapangan, serta (3) mengumpulkan data dan informasi dari penelitian.

Tahap selanjutnya yakni tahap analisis data dengan langkah - langkah yaitu reduksi data, penyajian data, dan menarik kesimpulan (verifikasi). Tahapan ini kemudian diakhiri dengan pemeriksaan atau pengecekan keabsahan data dengan tahapan (1) kepercayaan, menggunakan triangulasi sumber, teori dan metode, (2) keteralihan, dengan paparan menggunakan metode penulisan naratif, (3) kebergantungan, dengan menyajikan hasil penelitian secara sistematis serta (4) kepastian, yakni peneliti melakukan pengecekan dan konfirmasi ulang akan hasil penelitian yang didapatkan.

\section{Hasil Penelitian}

Hasil penelitian yang berkaitan dengan perencanaan pelatihan yaitu a) PPMS melakukan analisis kebutuhan dengan 
menyebar instrumen kepada calon sasaran pelatihan, mengadakan jejak pendapat dengan beberapa perwakilan dari tenaga kependidikan di DKI Jakarta. Dari hasil itulah dapat diketahui pelatihan apa yang dibutuhkan dalam upaya meningkatkan mutu tenaga kependidikan, diantaranya adalah 1) Peningkatan Motivasi dan Pembangunan Karakter bagi Pengawas TK, SD dan SMP, 2) Peningkatan Kompetensi Teknis Penyusunan Penelitian Tindakan Sekolah bagi Kepala SMA dan SMK, 3) Peningkatan Kompetensi Teknis bagi Calon Pengawas TK, SD dan SMP, b) Kemudian dalam tahap merencanakan pelatihan selanjutnya, kegiatan yang dilakukan oleh PPMS adalah penyusunan kerangka acuan, penyusunan proposal kegiatan, penyusunan program umum, pokok dan penunjang, penentuan kriteria peserta, penentuan kriteria penatar, hubungan instansional, pemanggilan peserta, penyusunan buku panduan, inventarisasi materi dan sarana-prasarana, c) Kegiatan perencanaan tersebut dapat menciptakan output yang berupa Kerangka Acuan Kegiatan dan Proposal Kegiatan Pelatihan, Panitia Pelaksana, nama Instruktur, Daftar Peserta yang akan diundang, Silabus dan Jadwal Pelatihan, Materi Pelatihan oleh Instruktur, Tata Tertib Pelatihan, Sarana dan Prasarana yang dibutuhkan.

Hasil penelitian yang berkaitan dengan pelaksanaan pelatihan yaitu a) pelaksanaan pelatihan didasarkan dari hasil perencanaan yaitu mengacu pada kerangka acuan kegiatan yang telah dibuat dan menetapkan peserta, kemudian dilaksanakan oleh Panitia dan difasilitatori instruktur yang kompeten, dan juga didukung oleh fasilitas yang memadai sehingga pelaksanaan pelatihan berjalan optimal, b) Dalam pelaksanaan kegiatan pelatihan ada istilah "IN 1", yaitu pembelajaran di kelas. Di dalam pembelajaran di kelas terdapat tahapan pelaksanaan pembelajaran yaitu Pembukaan
- Inti - Penutup. Dimana di dalam pembukaan terdapat kegiatan seperti mengucapkan salam, berkenalan dan menyampaikan tema pembelajaran sebagai stimulus respon bagi perserta. Kemudian adanya kegiatan Inti berupa penayangan materi dan menerangkan serta membahas materi. Di kegiatan Inti juga terdapat kegiatan seperti analisis dan studi kasus sehingga dapat dihasilkan kesimpulan dalam satu sesi. Yang terakhir adalah penutup yaitu terdiri dari kegiatan seperti meriview dan mengambil kesimpulan dari materi yang telah dipaparkan. Dalam beberapa kasus, Instruktur memberikan penugasan sebagai upaya evaluasi pelatihan yang telah Ia laksanakan, c) Setelah mengikuti kegiatan "IN 1" peserta wajib melaksanakan Proses “ON THE JOB LEARNING" dalam kegiatan ini peserta melakukan aktivitas di tempat kerjanya masing-masing melalui tuntunan instrumen dan modul yang telah disiapkan oleh panitia penyelenggara diklat sesuai dengan petunjuk narasumber. "ON THE JOB LEARNING" dilaksanakan dalam waktu kurang lebih dua hari, d) Selanjutnya peserta diklat berkumpul kembali pada kegiatan "IN 2" dengan membawa hasil kerja yang dilakukan dalam kegiatan "ON THE JOB LEARNING". Pada kegiatan ini peserta harus memaparkan hasil kerjanya di depan peserta lainnya secara bergantian sesuai dengan arahan instrumen dan modul terkait dengan pelatihan yang diikuti.

\section{Pembahasan}

PPMS dengan dibantu oleh Tim ahli dalam melakukan perencanaan pelatihan untuk meningkatkan mutu tenaga kependidikan adalah dengan mengadakan analisis kebutuhan pelatihan dengan melakukan jejak pendapat dan diskusi sehingga akan diketahui kebutuhan yang harus dipenuhi. Ini didukung oleh pendapat Daft (1997:214), "planning is 
the act of determining the organization's goals and the means for achieving them".

Kemudian perencanaan selanjutnya agar jelas siapa yang bertanggung jawab terhadap pelaksanaan suatu pelatihan, maka PPMS perlu menunjuk atau menetapkan seseorang yang bertanggung jawab sebagai pimpinan suatu pelatihan. Dalam setiap pelatihan memiliki masing-masing penanggungjawab yang berbeda yaitu dalam pelatihan Peningkatan Motivasi dan Pembangunan Karakter Bagi Pengawas TK, SD dan SMP, serta Pelatihan Peningkatan Kompetensi Teknis Bagi Calon Pengawas TK, SD, dan SMP ditanggungjawabi oleh Satuan Pelaksana Pengembangan Manajemen Pendidikan Dasar kemudian Pelatihan Peningkatan Kompetensi Teknis Penyusunan Penelitian Tindakan Sekolah Bagi Kepala SMA dan SMK ditanggungjawabi oleh Satuan Pelaksana Pengembangan Manajemen Pendidikan Menengah. Kemudian setelah adanya tim disusunlah kerangka acuan yang berisi tentang tujuan dan landasan pelatihan, sasaran pelatihan, subjek atau materi yang akan diberikan pada waktu pelatihan, jadwal dan lamanya pelatihan serta sarana prasarana yang menunjang pelatihan. Hal ini sejalan dengan pendapat Robbin dan Coulter (1999:200) yang menyatakan bahwa perencanaan adalah suatu proses yang melibatkan penentuan sasaran atau tujuan organisasi, menyusun strategi menyeluruh untuk mencapai sasaran yang ditetapkan, dan mengembangkan hierarki rencana secara menyeluruh untuk mengintegrasikan dan mengkoordinasikan kegiatan.

Dalam pelaksanaan pelatihan di PPMS, diawali dengan melihat output dari tahap perencanaan berupa hasil analisis kebutuhan berupa kerangka acuan dan proposal kegiatan dimana terdapat daftar peserta yang akan di undang, dan proses rekrutmen peserta yang didasarkan pada kriteria tertentu, yaitu Tenaga Kependidikan di wilayah DKI Jakarta yang belum pernah mengikuti pelatihan yang sama yang diselenggarakan oleh Dinas Pendidikan Prov. DKI Jakarta, nama-nama calon didasarkan pada daftar yang ada di Dinas Pendidikan Provinsi. Kemudian dilaksanakan pelatihan dengan pola IN1 - ON - IN2 yang diadakan sesuai jadwal yang telah direncanakan. Yang masing-masing pembelajarannya terdiri dari proses pembukaan - pemberian materi penutup. Ini sejalan dengan pendapat Majone dan Wildavsky yang dikutip Usman (2002:70), yang menyatakan bahwa pelaksanaan adalah suatu tindakan atau pelaksanaan dari sebuah rencana yang sudah disusun secara matang dan terperinci, implementasi biasanya dilakukan setelah perencanaan sudah dianggap siap.

Selain itu jika melihat pendapat dari Syukur (2000:398) tentang proses implementasi yang menyatakan sekurang-kurangnya terdapat tiga unsur penting dan mutlak yaitu:

1. Adanya program (kebijaksanaan) yang dilaksanakan;

2. Kelompok masyarakat yang menjadi sasaran dan manfaat dari program perubahan dan peningkatan;

3. Unsur pelaksanaan baik organisasi maupun perorangan yang bertanggung jawab dalam pengelolaan pelaksana dan pengawasan dari proses implementasi tersebut.

Pendapat di atas mendukung apa yang dilakukan PPMS, dibuktikan dengan program yang sudah ada dari hasil perencanaan melalui rapat koordinasi dan analisis kebutuhan. Semuanya pun dilakukan sesuai dengan kebijakan hukum yang sesuai yaitu mengacu pada Peraturan Gubernur DKI Jakarta NO.304 Tahun 2014 mengenai 
Pembentukan Organisasi dan Tata Kerja Pusat Pengembangan Manajemen Sekolah. Kemudian jika mengacu poin kedua adanya masyarakat yang menjadi sasaran program hal ini sesuai, yaitu sasaran pelatihan PPMS adalah tenaga kependidikan di lingkungan Dinas Pendidikan DKI Jakarta. Dan yang selanjutnya di dalam pelaksanaan pelatihan, di pimpim oleh koordinator yang bertanggungjawab terhadap pelaksanaannya, ada instruktur yang mengawasi langsung terhadap kegiatan pembelajaran dan mengevaluasi peserta baik mengadakan penungasan, OJL, pretes maupun post test. Ini sejalan dengan poin yang ketiga yaitu adanya unsur pelaksanaan baik organisasi maupun perorangan yang bertanggung jawab dalam pengelolaan pelaksana dan pengawasan dari proses implementasi tersebut.

\section{Kesimpulan}

1. Perencanaan pelatihan dalam upaya peningkatan mutu tenaga kependidikan di PPMS dilakukan dimulai dari diputuskannya APBD dan terlihat anggaran pelatihan, PPMS kemudian mengadakan analisis kebutuhan pelatihan, jejak pendapat dengan calon sasaran pelatihan, Rapat Koordinasi antara Panitia dan Satuan Pelaksana, Tim Instruktur yang sudah mendapatkan kepercayaan yang kemudian di laporkan kepada Kepala PPMS, Menentukan tujuan pelatihan, Menentukan sasaran pelatihan, Menentukan Subjek Materi, Waktu, dan Jumlah Peserta, Menentukan secara lebih spesifik Instruktur dengan materi yang sesuai dengan keahlian bidangnya. Dari proses inilah dihasilkan Kerangka Acuan Kegiatan dan Proposal Kegiatan, Kriteria Peserta dan Kriteria
Instruktur, Daftar Peserta yang akan diundang, Silabus dan Jadwal Pelatihan, Materi Pelatihan oleh Instruktur, Tata Tertib Pelatihan serta Sarana dan Prasarana yang dibutuhkan. Perencanaan pelatihan dilakukan oleh Tim yang terdiri dari Satuan Pelaksana, Instruktur yang sudah menjalin kerjasama, dan tenaga lain yang dipercaya.

2. Dalam melaksanakan pelatihan, PPMS mengandalkan Panduan atau silabus dan Kerangka Acuan Kegiatan (KAK) dalam melaksanakan pelatihan. Dengan adanya panduan dan komitmen yang kuat, tujuan pelatihan akan tercapai walau tidak dipungkiri hambatan terjadi di dalam pelaksanaan pelatihan. Dalam pelatihan satu tahun ini, yaitu 2015, PPMS berhasil mengadakan 12 pelatihan dengan hasil evaluasi yang cukup baik yang didapat dari instrument evaluasi yang diisi oleh Peserta pelatihan. Pihak yang paling berperan dalam melaksanakan pelatihan adalah Satuan Pelaksana baik Pengembang Pendidikan Dasar maupun Menengah. Tahapan Pelaksanaan terdiri dari tahap pemberian pre tes IN 1 - OJL - IN 2 - post tes hingga sampai hasil evaluasi keluar berupa sertifikat penilaian untuk para peserta. Output yang dihasilkan dalam pelaksanaan pelatihan berupa Laporan Pertanggungjawaban berserta dokumentasi foto kegiatan pelatihan.

\section{Saran}

1. Kepada Kepala Pusat, saran yang dapat diberikan dalam melakukan analisis kebutuhan adalah ikut turut andil dalam jejak pendapat dengan 
Satuan Pelaksana sehingga kebutuhan pelatihan diketahui dan memudahkan dalam mengambil keputusan. Sebagai Kepala Pusat tentunya harus mengetahui dan melaksanakan tugas sesuai deskripsi pekerjaan meskipun berlatar belakang berbeda dengan dunia pelatihan khususnya di bidang pendidikan. Dan dalam pelaksanaan pelatihan Kepala Pusat sebagai supervisor jalannya kegiatan sebaiknya melakukan pengamatan secara langsung dan monitoring yang berkelanjutan untuk dijadikan bahan evaluasi kegiatan mendatang.

2. Kepada Satuan Pelaksana, saran yang dapat diberikan adalah sebagai pihak yang mengupdate kurikulum dan materi sebaiknya ikut menetapkan materi bersama tim instruktur sehingga tujuan kegiatan yang diinginkan dapat selaras dengan materi yang disampaikan oleh Instruktur. Dalam pelaksanaan pelatihan Satuan Pelaksana sebaiknya lebih mengawasi kembali atas kehadiran dan kedisiplinan peserta serta Instruktur yang sudah ditetapkan. Sehingga kegiatan pelatihan terlaksana sebagaimana mestinya.

3. Kepada instruktur, saran yang dapat diberikan adalah sebagai salah satu faktor penting dalam pembelajaran di kelas sebaiknya menyiapkan lebih detail terkait materi yang lebih bervariasi dan tentu saja dalam pelaksanaanya pun dilakukan dengan metode yang uptodate sehingga menarik perhatian peserta dan tujuan pembelajaran pun tercapai.

\section{Daftar Pustaka}

Daft,Richard L. (1997). Management. New York: The Dryden Press

Daud, Jaleluddin. (2004). Prosedur

Perencanaan (Planning Procedure). Medan: e-USU Universitas Sumatera Utara.

Harsono, Hanifah. (2002). Implementasi Kebijakan dan Politik. Bandung: PT. Mutiara Sumber Widya.

Jones, Gareth R. dan Jennifer M. George. (2003). Contemporary Management. New York: McGraw-Hill

Milkovich, George T. dan DI Boudreau. (1994). Human Resource Management. Sydney: IRWIN

Omocharu, Vincent K. dan Joel E. Ross. (1994). Principles of Total Quality, Florida: St. Lucie Press

Robbins, Stephen P. dan Mary Coulter. (1999). Manajemen Jilid 1 Edisi Keenam. Diterjemahkan oleh: T. Hermaya. Jakarta: PT. Prenhallindo

Ross, Joel R. (1995). Total Quality Management, Text, Case, and Readings. Singapore: S.S Mubaruk \& Brothers Pte Ltd.,

Setiawan, Guntur. (2004). Implementasi

Dalam Birokrasi Pembangunan. Jakarta: Raja Grafindo

Stoner, James A. F., R. Edward Freeman, dan Daniel R. Gilbert. (1994). Management. London: Prentice - Hall International, Inc.

Syukur, Abdullah. (2000). Kumpulan Makalah "Research Implementasi Latar Belakang Konsep Pendekatan dan Relevansinya Dalam Pembangunan”. Ujung Pandang: Persadi 
Tjiptono, Fandy dan stiner Diana. (2013).

Total Quality Management (TQM) Edisi

Revisi. Yogyakarta: Andi

Tohari, Ahmad. (2015). Membangun

Budaya Organisasi Pada Instansi

Pemerintahan. Yogyakarta: CV Budi Utama
Usman, Nurdin. (2002). Konteks

Implementasi Berbasis Kurikulum. Jakarta:

PT. Raja Grafindo Persada

Wahab, Solichin Abdul. (2001). Analisis

Kebijakan Dari Formulasi ke Implementasi

Kebijakan Negara. Jakarta: Bumi Aksara. 